\title{
Total enteroscopy by antegrade motorized spiral enteroscopy under conscious sedation for acute overt obscure gastrointestinal bleeding
}

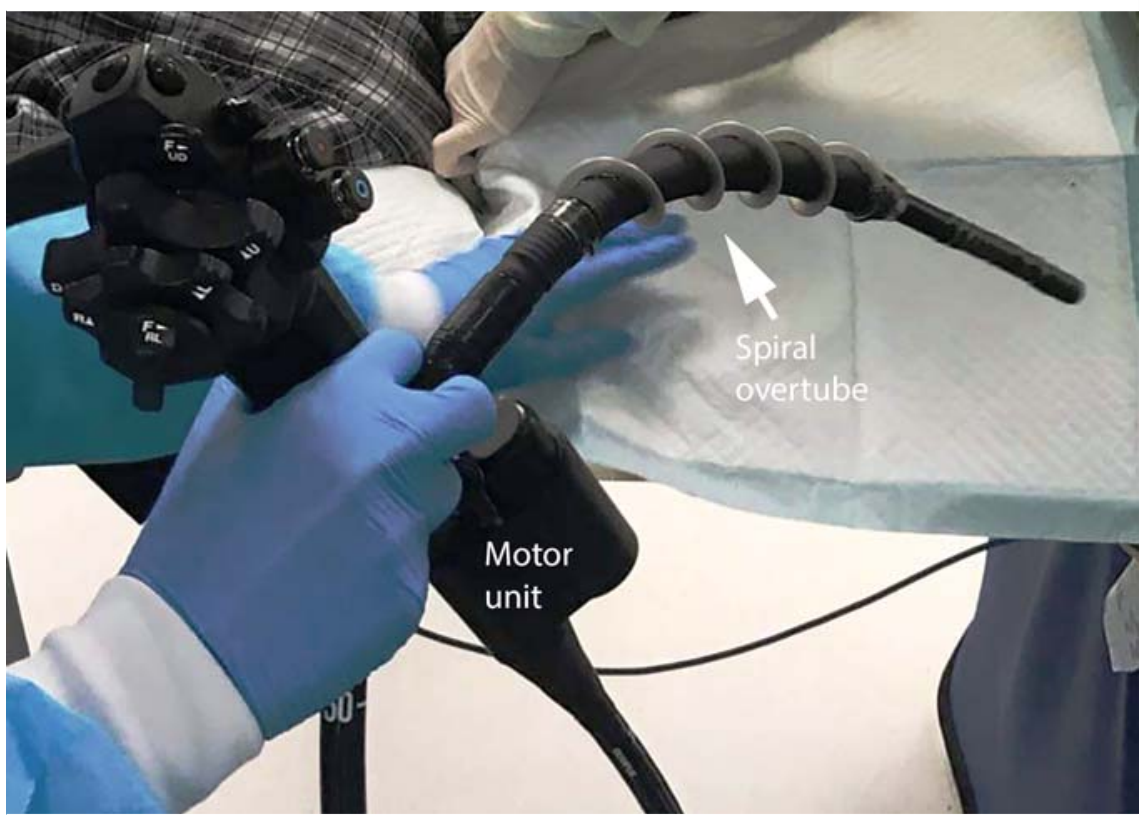

- Fig. 1 Photograph of the motor unit and short spiral overtube on the motorized spiral enteroscope.

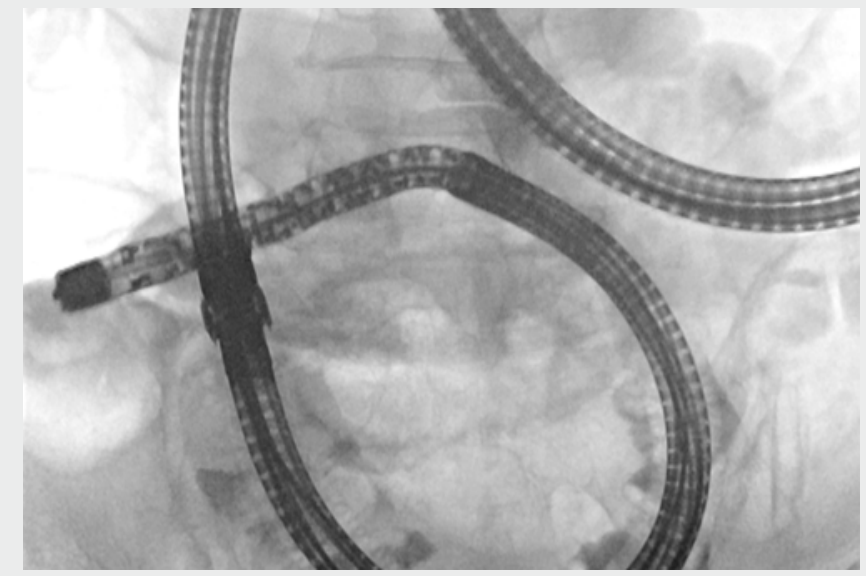

Video 1 Total small-bowel evaluation by antegrade motorized spiral enteroscopy in a patient under conscious sedation who had overt obscure gastrointestinal bleeding from ileal ulcers related to a recent episode of Campylobacter gastroenteritis.

In patients requiring deep enteroscopy, balloon overtube-assisted enteroscopy and spiral overtube-assisted enteroscopy are generally the procedures of choice, but each has its own strengths and limitations in terms of total enteroscopy rate and procedure time [1]. Recently, a novel motorized spiral enteroscope

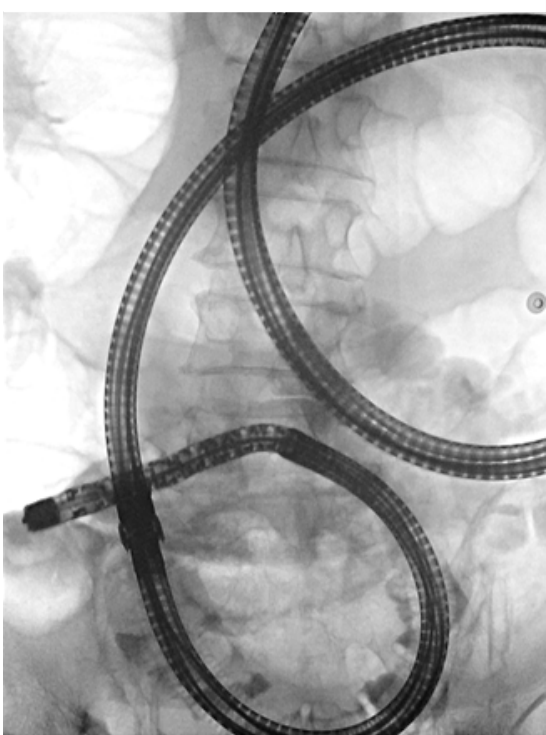

Fig. 2 Fluoroscopic view showing the configuration of the motorized spiral enteroscope with its tip in the cecum.

(MSE; Olympus, Tokyo, Japan) equipped with a short motor-driven spiral overtube has become available (\$Fig. 1) [25]. To date, the reported total enteroscopies, whether by antegrade approach alone or combined antegrade and retrograde approaches, have been performed with the patient under general anesthesia or deep sedation [5]. To the best of our knowledge, we here report the first case of total enteroscopy by antegrade MSE being performed for overt obscure gastrointestinal (GI) bleeding in a patient under conscious sedation.

An 87-year-old man with recent hospitalization for Campylobacter gastroenteritis presented with hematochezia and a drop in hemoglobin from normal to $5.4 \mathrm{~g} / \mathrm{dL}$. After he had been resuscitated, upper $\mathrm{Gl}$ endoscopy and colonoscopy were performed, which showed small clean-based gastric ulcers, maroon-colored blood and clots throughout the colon and terminal ileum, and several non-bleeding ulcers in the terminal ileum. 

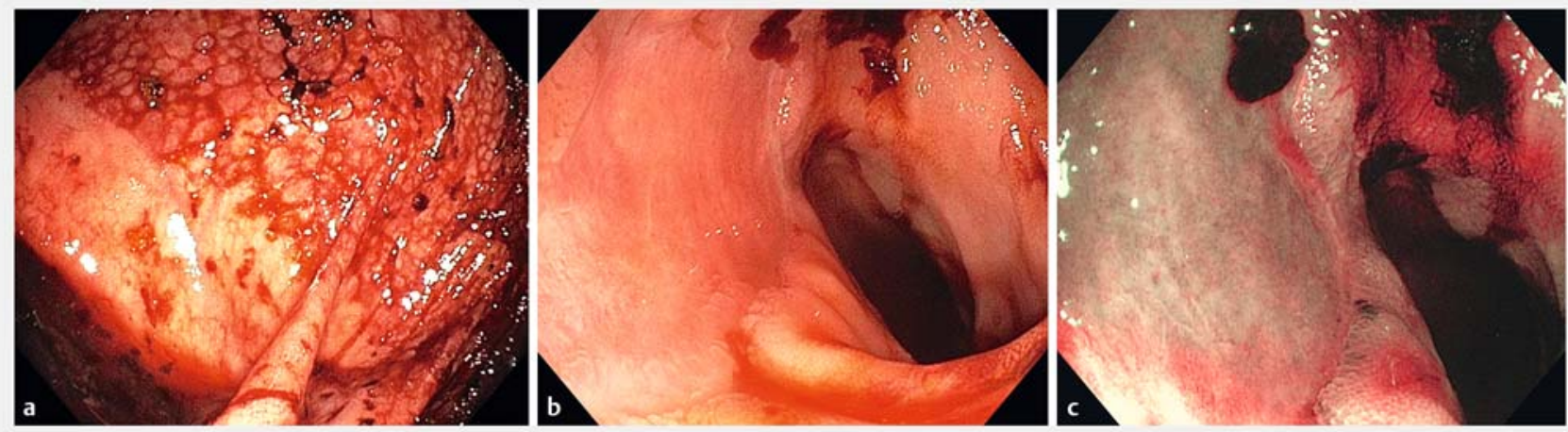

- Fig. 3 Views during antegrade motorized spiral enteroscopy showing: a the cecum with maroon-colored blood present; $\mathbf{b}$ a large ulcer in the distal ileum, presumed to be related to recent episode of Campylobacter gastroenteritis; $\mathbf{c}$ the distal ileal ulcers viewed by narrow-band imaging.

Despite having initially been stabilized, the patient developed recurrent bleeding and shock. Urgent celiac and mesenteric angiography did not reveal any active extravasation of contrast. Because of the high clinical suspicion of smallbowel bleeding, antegrade MSE was subsequently performed with the patient under conscious sedation with midazolam and pethidine. Total enteroscopy was achieved ( $\mathbf{F i g . 2}$ ) with a procedure time of 58 minutes from the ligament of Treitz to the cecum. Adherent clots and multiple non-bleeding ulcers up to $2 \mathrm{~cm}$ in size were visualized in the mid-to-distal ileum and were biopsied ( $\mathbf{F i g . 3}$; - Video 1). The patient tolerated MSE well and there were no adverse events. The small-bowel ulcer biopsies revealed acute inflammation without evidence of infectious organisms, malignancy, or chronicity. Given the lack of prior aspirin or NSAID use, the ulcers were presumed to be related to the patient's recent Campylobacter gastroenteritis. The patient was eventually discharged in stable condition, without further episodes of bleeding.

Endoscopy_UCTN_Code_TTT_1AP_2AD

\section{Competing interests}

Raymond S. Y. Tang: medical advisory board member (Boston Scientific), Philip W.Y. Chiu: consultant (Olympus, Boston Scientific), scientific advisory board member (Aptorum, EndoMASTER).
The authors

Raymond S. Y. Tang', Marc T. L. Wong', Jimmy C. T. Lai ${ }^{1}$, Philip W. Y. Chiu ${ }^{1,2}$

1 Institute of Digestive Disease, The Chinese University of Hong Kong, Prince of Wales Hospital, Hong Kong, China

2 Department of Surgery, The Chinese University of Hong Kong, Prince of Wales Hospital, Hong Kong, China

\section{Corresponding author}

\section{Raymond S. Y. Tang, MD}

Institute of Digestive Disease, The Chinese University of Hong Kong, 4M, 4/F, Day Treatment Block, Prince of Wales Hospital, Shatin, New Territories, Hong Kong, China raymondtang@cuhk.edu.hk

\section{References}

[1] Khashab MA, Pasha SF, Muthusamy VR et al. The role of deep enteroscopy in the management of small-bowel disorders. Gastrointest Endosc 2015; 82: 600-607

[2] Neuhaus H, Beyna T, Schneider M et al. Novel motorized spiral enteroscopy: first clinical case. VideoGIE 2016; 1: 32-33

[3] Beyna T, Schneider M, Arvanitakis M et al. Novel motorized spiral endoscopy: A twocenter prospective clinical trial. Dig Endosc 2017; 29: 7-28

[4] Beyna T, Schneider M, Pullmann D et al. Motorized spiral colonoscopy: a first singlecenter feasibility trial. Endoscopy 2018; 50: 518-523

[5] Beyna T, Arvanitakis M, Schneider M et al. First prospective clinical trial on total motorized spiral enteroscopy (TMSET). Gastrointest Endosc 2019; 89: AB48

\section{Bibliography}

DOI https://doi.org/10.1055/a-1089-7506

Published online: 29.1.2020

Endoscopy 2020; 52: E251-E252

(c) Georg Thieme Verlag KG

Stuttgart · New York

ISSN 0013-726X

\section{ENDOSCOPY E-VIDEOS}

https://eref.thieme.de/e-videos

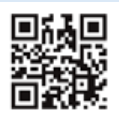

Endoscopy E-Videos is a free access online section, reporting on interesting cases and new techniques in gastroenterological endoscopy. All papers include a high quality video and all contributions are freely accessible online.

This section has its own submission website at https://mc.manuscriptcentral.com/e-videos 